\title{
Bir Öz Düzenleme Becerisi Olan Dikkat Kontrolü ile Öznel İyi Oluș ve Ruminasyon Arasındaki İlişkinin İncelenmesi ${ }^{1}$
}

\author{
Sema YAZICI KABADAYI ${ }^{1}$ (iD), Hümeyra ÖZTÜRK ${ }^{2}$ (iD
}

${ }^{1}$ Recep Tayyip Erdoğan Üniversitesi, Rize, sema.yazici@erdogan.edu.tr

${ }^{2}$ Psikolojik Danışman, Konya, humeyrraa61@gmail.com

\begin{tabular}{|c|c|}
\hline Makale Bilgileri & ÖZ \\
\hline $\begin{array}{l}\text { Makale Geçmişi } \\
\text { Geliş: } 15.08 .2020 \\
\text { Kabul: } 10.12 .2020 \\
\text { Yayın: } 29.12 .2020 \\
\text { Anahtar Kelimeler: } \\
\text { Dikkat kontrolü } \\
\text { Öznel iyi oluş } \\
\text { Ruminasyon } \\
\text { Üniversite öğrencileri }\end{array}$ & $\begin{array}{l}\text { Bu araştırma, üniversite öğrencilerinin dikkat kontrolleri ile öznel iyi oluş ve ruminasyon düzeyleri } \\
\text { arasındaki ilişkiyi incelenmek amacıyla gerçekleştirilmiştir. Araştırmanın çalışma grubu, Türkiye'nin } \\
\text { çeşitli üniversitelerinde öğrenim gören ve araştırmaya gönüllü olarak katılan } 370 \text { öğrenciden oluşmaktadır. } \\
\text { Verilerin toplanmasında Öz Düzenlemenin Dikkat Kontrolü Boyutu Ölçeği, Öznel İyi Oluş Ölçeği, } \\
\text { Ruminatif Düşünce Biçimi Ölçeği ve araştırmacıların hazırladığ1 kişisel bilgi formu kullanılmıștır. Veri } \\
\text { analizinde öğrencilerin dikkat kontrol düzeyleri ile öznel iyi oluş ve ruminasyon arasındaki ilişkiyi } \\
\text { incelemek için Pearson korelasyonu ve basit doğrusal regresyon analizi kullanılmıştır. Edinilen bulgulara } \\
\text { göre dikkat kontrolünün, öznel iyi oluş ile orta düzeyde olumlu yönde ilişkili olduğu ve öznel iyi oluşun } \\
\text { dikkat kontrolünü anlamlı şekilde yordadığı bulunmuştur. Elde edilen bulgular literatür doğrultusunda } \\
\text { tartışılarak, araştırmacılar ve uygulayıcılar için öneriler getirilmiştir. }\end{array}$ \\
\hline
\end{tabular}

\section{Investigation of the Relationship Between Control Dimension of Self Regulation and Subjective Well-being Rumination}

\begin{tabular}{|c|c|}
\hline Article Info & ABSTRACT \\
\hline Article History & \\
\hline Received: 15.08 .2020 & subjective well-being and rumination levels. The sample of the study consisted of 370 undergraduate \\
\hline Accepted: 10.12 .2020 & students studying in various universities across Turkey. Attention Control Dimension Scale of Self- \\
\hline Published: 29.12 .2020 & Regulation, Subjective Well-Being Scale, Ruminative Thinking Scale and personal information form \\
\hline Keywords: & $\begin{array}{l}\text { prepared by researchers were used to collect data. In data analysis, Pearson correlation and simple linear } \\
\text { regression analysis were used to examine the relationship between students' attention control levels and }\end{array}$ \\
\hline Attention control & subjective well-being and rumination. According to the obtained findings, it was found that attention \\
\hline Subjective well-being & control is positively associated with subjective well-being at a moderate level and subjective well-being \\
\hline Rumination & with the literature and \\
\hline University student & \\
\hline
\end{tabular}

* Bu çalışma 21. Uluslararası Psikolojik Danışma ve Rehberlik Kongresi'nde özet bildiri olarak sunulmuştur.

"This article is licensed under a Creative Commons Attribution-NonCommercial 4.0 International License (CC BY-NC 4.0)"

Atıf/Citation: Yazıcı Kabadayı, S. \& Öztürk, H. (2020). Bir öz düzenleme becerisi olan dikkat kontrolü ile öznel iyi oluş ve ruminasyon arasındaki ilişkinin incelenmesi. Necmettin Erbakan Üniversitesi Ereğli Eğitim Fakültesi Dergisi, 2(2), $230-242$. 


\section{GíRiș}

Bulunduğu çevreye uyum sağlama çabasında olan bireyler için davranış ve duygu yönetiminde öz düzenleme becerisi son derece önemli bir kavramdır (Duran, 2019). İnsanın hayatta kalması için önemli bir unsur olduğu düşünülen öz düzenleme, bireysel hedeflere ulaşmak amacıyla döngüsel şekilde kullanılan bağlama özgü süreçleri ifade etmektedir. Üst bilişsel bilgi ve beceriden daha fazlasını içeren bu süreçler duygusal ve davranışsal ögeleri de içerir (Bakır, 2016; Çevik, Haşlaman, Mumcu ve Gökçearslan, 2015; Zimmerman, 2000). Sosyal psikoloji, kişilik psikolojisi ve bilişsel psikoloji gibi alanların ele aldığı öz düzenleme kavramının incelenmesine yönelik iki teorik yaklaşımdan söz edilebilir. Bunlardan ilki olan süreç yaklaşımı öz düzenlemeyi, zaman içinde gelişen ve bireylerin hedefleriyle bağlantılı süreçler olarak açıklarken; diğer önemli teorik yaklaşım kişilik psikolojisine dayanır ve öz düzenlemeyi bireysel bir kişilik özelliği olarak değerlendirir (Diehl, Semegon ve Schwarzer, 2006; Hofmann, Schmeichel ve Baddeley, 2012). Bireyin kişisel bir özelliği olan ve kendi duygu ve davranışlarını düzenleme yeteneklerini ifade eden öz düzenleme, bebeklik ve erken çocukluk dönemlerinden itibaren gelişmeye başlamaktadır. Öz düzenlemenin gelişimi üzerinde genetik yatkınlık, tecrübe ve sosyal faktörlerin önemli etkileri olduğu ifade edilmektedir (Berger, Kofman, Livneh ve Henik, 2007). Öz düzenleme becerisi gelişmiş bireylerin ise kendi duygu, düşünce ve davranışlarını organize etme konusunda daha üstün bir performans sergileyebilecekleri ifade edilmektedir (Alçay, 2019; Yay, 2018).

Öz düzenleme yapısının kilit yönü olan dikkat (Berger, Kofman, Livneh ve Henik, 2007); farkındalık, alg1, seçim yapma, bellek, dil, öğrenme gibi kavramlarla ilgili çok bileşenli bir yapıdır. Dikkat, belirli bir nesneyi veya olayı algılayabilmeyi, arzulanan bir hedefi gerçekleştirebilmeyi ya da dikkat sürecini nesneye, olaya veya hedefe bilinçli bir şekilde yöneltmeyi ifade etmektedir (Aydın, 2004; Soysal, Yalçın ve Can, 2008). Davranışın bilişsel kontrolünü ele alan çoğu model işe dikkatle başlar, çünkü bilgiyi işlemenin ilk aşaması fark etmektir ve bu da dikkat ile mümkündür. Öz düzenlemenin de merkezinde yer alan dikkat kontrolü, çocukların ve yetişkinlerin, düşünce ve duygularını düzenlemelerine olanak sağlayan yetenekleri ifade eder ve bu yetenekler öz düzenlemenin bütün alanlarında önemli bir unsur olarak değerlendirilmektedir (Baumeister ve Heatherton, 1996; Rueda, Posner ve Rothbart, 2004). Bireylerin engeller karşısında dahi hedeflerine odaklanmasını sağlayan ve öz düzenlemenin bir bileşeni olan dikkat kontrolü (Luszczynska, Diehl, Gutiérrez-Dona, Kuusinen \& Schwarzer, 2004), bir insanın zihnini dağıtan iç ve dış uyarıcıları düzenleme ve kontrol etme, arzulanan hedef veya sonuçlara ulaşma ve odaklanma yeteneği olarak tanımlanır. Dürtüsel davranışın zıttı ve çoğu karmaşık eylemin ayrılmaz bir parçası olan dikkat kontrolü, öz düzenlemenin düzenleyici bir bileşeni olan kişilik değişkenini temsil eder (Diehl, Semegon ve Schwarzer, 2006).

Bir kişinin hedefe olan bağlılı̆̆ını gösteren dikkat kontrolünü sağlama konusunda başarılı olan bireylerin, hedeflere ulaşma konusunda daha kararlı oldukları, hedeflere ulaşma konusunda daha çabuk harekete geçtikleri ve hedefe ulaşmak için zaman ve çaba harcamaya daha istekli oldukları ifade edilmektedir (Diehl, Semegon ve Schwarzer, 2006). Dikkati herhangi bir şeye yoğunlaştırma sürecinde, dikkati dağıtan her türlü uyaranı kontrol altına alma kabiliyeti, bireyin etkinliklerini etkili şekilde düzenlediğinin bir işareti olarak görülmektedir (Şata, 2017) ve etkili dikkat yönetiminin, istenmeyen sonuçların ortaya çıkmasını nispeten ortadan kaldırdığı ifade edilmektedir (Baumeister ve Heatherton, 1996). Dikkat kontrolü, hedefe ulaşmayı sağlayan bilgilerin işlenmesini kolaylaştırırken aksi yönde etkisi olan bilgilerin işlenmesini engeller. Bunun yanı sıra dikkat kontrolünü sağlayarak göreve odaklanmak ve olumlu duygusal dengeyi korumak, hedefe yönelik davranışın sürdürülmesine yardımcı olur ve sonraki görevleri yerine getirmeyi kolaylaştırır. Ortaya çıkan engellere rağmen mevcut önceliğe odaklanarak dikkat kontrolünü sağlamak zor bir öz düzenleme sürecidir (Luszczynska vd., 2004).

Dikkat kontrol düzeyi yüksek bireylerin, daha az endişeli oldukları ve negatif duygulanıma daha az 
kapıldıkları ifade edilmektedir (Diehl, Semegon ve Schwarzer, 2006; Eisenberg, Fabes, Guthrie \& Reiser, 2000). Bunun yanı sıra yapılan çalışmalarda, dikkat kontrolü ile depresyon, kaygı, intihar düşünceleri ve saldırganlık gibi çeşitli psikopatolojik durumların negatif yönde ilişkili olduğu ifade edilmektedir (Keilp vd., 2013; Muris, Meesters ve Rompelberg, 2007; Reinholdt-Dunne, Mogg ve Bradley, 2013). Kişinin olumsuz duygularını kontrol etme yeteneğini de temsil eden öz düzenlemenin yüksek olması daha düşük olumsuz duygulanımları içermekte, bunun yanı sıra öz düzenlemenin öznel iyi oluş ile pozitif yönde yüksek düzeyde ilişkili olduğu ifade edilmektedir (Luszczynska vd., 2004). Bütün bu bulgular öz düzenlemenin bir boyutu olan dikkat kontrolünün bireylerin psikolojik sağlıklarıyla yakından ilişkili olduğunu ve bireylerin dünyaya ilişkin öznel değerlendirmelerinde dikkat kontrolünün önemli bir faktör olabileceğini göstermektedir.

İnsanların yaşamlarına ilişkin duygusal ve bilişsel değerlendirmelerini ve yaşam memnuniyetini içeren bir kavram olarak tanımlanan öznel iyi oluş (Diener, 2000; Diener, Oishi ve Lucas, 2003) kavramının dikkat kontrolü ile ilişkili bir değişken olabileceği düşünülmektedir. Bireyin hayatına dair durumlara verdiği duygusal tepkilerin ve değerlendirmelerin bir sonucu olarak ortaya çıkan öznel iyi oluş; olumlu duygulanımın görece yüksek, olumsuz duygulanımın ise düşük düzeyde olması ve yaşam doyumundan oluşan üçlü bir yapıyı ifade eder (Diener, 2000; Diener ve Chan, 2011; Myers ve Deiner, 1995). Bireyin yaşamında, olumlu duyguları, olumsuz duygularından yüksekse ve bireyin yaşam kalitesine dair yargısı olumlu ise öznel iyi oluş düzeyinin yüksek olduğu belirtilmektedir (Erdost, 2005). Yüksek düzeyde öznel iyi oluşun zaman içinde kararlılık gösteren bir özellik olduğu, iyi yaşam ve iyi toplum için gerekli olduğu fakat yeterli olmadığı düşünülmektedir (Diener, Oishi ve Lucas, 2003).

Genellikle bilince açılan kapı olarak adlandırılan dikkatin seçici dikkat boyutunun öznel iyi oluş eğilimlerini destekleyebileceği veya zayıflatabileceği düşünülmektedir. Daha yüksek öznel iyi oluşun daha geniş uzamsal dikkat ve dikkat esnekliği ile ilişkili olduğu ifade edilmektedir (Gasper ve Clore, 2002; Robinson ve Compton, 2008). Öznel iyi oluşu yüksek bireylerin bilişsel süreçleri incelendiğinde dikkatlerinin olumlu bilgilere yönlendirildiği, olumlu bilgileri tercih eden sınıflama eğilimlerine sahip oldukları, olumlu bilgileri tercih eden öncelikler belirledikleri ifade edilmektedir (Robinson ve Compton, 2008). Bu durum bireylerin öznel iyi oluş düzeylerinin dikkat süreçleriyle yakından ilişkili olabileceğini bir göstergesi olarak değerlendirilmektedir. Dikkat kontrolünde önemli bir yere sahip olan hedef kavramının benzer şekilde öznel iyi oluş ile de ilişkili olduğunu gösteren araştırma bulguları mevcuttur. Brunstein (1993), anlamlı hedeflerin başarılı bir şekilde takip edilmesinin öznel iyi oluşun geliştirilmesi ve sürdürülmesinde önemli bir rol oynadığını ifade etmektedir. Bireyin öznel iyi oluşuna ön koşul, kişisel hedeflerinin ne ölçüde gerçekleşeceğidir. Bu durum öznel iyi oluş ile dikkat düzenlemenin de önemli bir bileşeni olan hedefe bağlılık arasında pozitif veya negatif yönde bir ilişki olabileceğini göstermektedir.

Dikkat kontrolü ile ilişkili olabileceği düşünülen bir diğer kavram olan ruminasyon; bireyin kişisel problemleri, gönülsüz ve kasıtlı olmayan deneyimleri hakkında yinelenen düşünceleridir (Wells, 2003). Hoeksema, Wisco ve Lyubomirsky, (2008) ruminasyonu özel içerikli düşüncelerden çok, birinin duygu ve düşünceleri hakkında 1srarla düşünme süreci olarak tanımlarlar. Düşünceler üzerindeki depresif etkileri genişleterek, bireylerin olağan durumlarını değerlendirmek için negatif düşünce ve anıları kullanmalarını arttıran ruminasyon bazen düşünmeyi karamsar ve kaderci yaparak, problemlerle etkili bir şekilde başa çıkmayı güçleştirmektedir. Aynı zamanda ruminasyon araçsal davranışa karışarak stresli durumların artışına yol açmaktadır. Olumsuz süreçler hakkında tekrarlayan düşünceler olarak tanımlanan ruminasyonun ciddi olumsuz sonuçlara yol açtığı bulunmuştur (Whitmer ve Gotlib, 2013).

Donaldson, Lam ve Mathews (2007), dikkat ve ruminasyon arasında negatif yönlü bir ilişki olduğunu ifade etmektedirler. Benzer şekilde Suh (2016) da ruminasyonun olumsuz etkilerinin dikkat dağınıklığına sebep olabileceğini ifade etmektedir. Whitmer ve Gotlib (2013) ise dikkat kapsamının genişliğinin ruminasyonu azaltıcı bir etkiye sahip olduğunu öne sürmektedir. Bu durum ruminasyonun davranışsal ve duyuşsal yönlerin yanı sıra bilişsel boyutunun ve bu boyutta da dikkatin önemli bir unsur olduğunu gösterir niteliktedir. Tekrar tekrar ve pasif olarak sıkıntı semptomlarına, ayrıca belirtilen semptomların olası 
nedenleri ya da sonuçlarına odaklanmayı içeren ruminasyonun (Nolen-Hoeksema, Wisco ve Lyubomirsky, 2008) bireylerin hedeflere ulaşma veya herhangi bir konuya odaklanma sürecinde dikkat kontrol düzeyi ile negatif yönde ilişkili olabileceği düşünülmektedir.

Üniversite çağına gelmiş ve belirli bir bilişsel yeterliğe sahip olduğu düşünülen bireyler için öz düzenleme ve dikkat kontrolünün son derece önemli olduğu düşünülmektedir. Çünkü Ericson'a göre üniversite öğrencilerinin bulunduğu çağda; yakın ilişkiler kurabilme, iş hayatına atılma-sürdürebilme gibi her dönemin kendine özgü gerçekleştirilmesi gereken bir takım görev ve ödevleri vardır. Bireyler bu görevleri gerçekleştiremedikleri sürece iyi oluş derecelerinin olumsuz etkileneceği ayrıca etkili başa çıkabilmeyi sağlayamayıp olaylar üzerinde isteksizce, sürekli düşünmelerinin dikkat dağınıklığına sebep olacağı ve dikkat kontrolünü olumsuz yönde etkileyebileceği düşünülmektedir. Bu durumda hedeflere etkili bir şekilde ulaşmak amacıyla dikkatin etkili bir şekilde işe koşulması ve dikkat kontrolünü etkileyen faktörlerin ele alınması gerekmektedir. Nitekim literatürde dikkat kontrolünü ele alan çalışmaların sınırlı sayıda olduğu, var olan çalışmaların ise psikoloji alanının dışında olduğu görülmektedir. Çok bileşenli bir yapıya sahip olan dikkatin etkilerinin de çok yönlü olacağı düşünülerek, farklı bağlamlarda araştırılmasının önemli katkılar sağlayacağı düşünülmektedir. Dikkat kontrolünün bireylerin hayatındaki çok yönlü varlığının yine benzer şekilde bireylerin yaşamlarına ilişkin bilişsel ve duyuşsal değerlendirmelerini içeren öznel iyi oluş kavramıyla da ilişkili olabileceği düşünülmektedir. Öznel iyi oluşun aksine bazı olumsuz deneyim ve duygularla ilişkilendirilen ruminatif düşünmenin de benzer şekilde dikkat kontrolü ile ilişkili bir unsur olabileceği düşünülmektedir. Bireyin hayatının her noktasında istendik yönde ilerleme kaydedebilmesi, uyum sağlayabilmesi, kişisel/sosyal/mesleki anlamda başarılı olabilmesi için öz düzenleme becerisine sahip olmanın önemli olduğu düşünülmektedir. Bu anlamda önemli bir faktör olan dikkat kontrolünü temel alan çalışmaların ise yetersiz olduğu görülmektedir. Dolayısıyla bu çalışmada önemli bir faktör olarak değerlendirilen dikkat kontrolünün, psikolojik etkileri anlamında farklı yönlerini gösteren öznel iyi oluş ve ruminasyon kavramlarıyla ilişkisinin ortaya konulması hedeflenmektedir. Bu yolla dikkat kontrolüne kaynaklık edebilecek psikolojik özellikle kavramların ortaya konması amaçlanmaktadır. Özellikle dikkat kontrolü üzerinde yapılmış akademik çalışmaların kısıtlılığı göz önünde bulundurulduğunda bu araştırmanın literatüre katkı sağlayacağı düşünülmektedir. Bunun yanı sıra bu çalışma ile zihinsel faaliyetlerin gerçekleştirilmesinde dikkatin önemli bir payı olduğunu konu edinen bilişsel psikolojiye, dikkat kontrolünü etkileyen farklı değişkenler hakkında bilgi toplayarak katkı sağlayacağı düşünülmektedir.

Bu doğrultuda bu çalışmasının amacı, öz düzenlemenin önemli bir bileşeni olan dikkat kontrolü ile öznel iyi oluş ve ruminasyon kavramlarının birbirleriyle olan ilişkilerinin incelenmesi olarak belirlenmiştir. Bu amaçla ilişkili olarak şu sorulara cevap aranacaktır:

1. Öznel iyi oluş, ruminasyon ve dikkat kontrolü arasında istatistiksel olarak anlamlı ilişkiler var mıdır?

2. Öznel iyi oluş ve ruminasyon düzeyleri dikkat kontrolünü anlamlı düzeyde yordamakta mıdır?

\section{YÖNTEM}

\section{Araştırma Modeli}

Bu çalışmada korelasyonel araştırma modelinden yararlanılmıştır. Korelasyonel araştırmalar, iki veya ikiden daha fazla değişkenin aralarında ilişki olup olmadığını ortaya koymak ve çalışmanın değişkenlerinin nedensonuçlarına ilişkin ipucu yakalamak amacıyla yapılan araştırmalardır (Büyüköztürk, Çakmak, Akgün, Karadeniz ve Demirel, 2017). Araştırmanın bağımlı değişkeni dikkat kontrolü; bağımsız değişkenleri ise öznel iyi oluş ve ruminasyondur.

\section{Çalışma Grubu}

Bu araştırmada çalışma grubunu 2018-2019 eğitim öğretim yılı içinde Türkiye'nin çeşitli üniversitelerinde öğrenim görmekte olan, araştırmacı tarafından ulaşılabilen ve araştırmaya katılmaya gönüllü, 370 üniversite öğrencisi oluşturmaktadır. Çalışma grubunun sosyo-demografik yapısına ilişkin betimsel istatistiklere Tablo 
1 'de yer verilmektedir.

Tablo 1.

Katılımcılara İlişkin Sosyo-Demografik Özellikler

\begin{tabular}{lll}
\hline Değişkenler & Frekans & Yüzde \\
Cinsiyet & & 77,3 \\
Kadın & 286 & 22,7 \\
Erkek & 84 & 17,3 \\
Okudukları Bölüm Türü & & 40,3 \\
Sayısal & 64 & 42,1 \\
Sözel & 149 & 0,3 \\
Eşit ağırlık & 156 & \\
Belirtilmemiş & 1 & 3,8 \\
Algılanan Sosyo-Ekonomik Düzey & & 84,3 \\
İyi & 14 & 11,9 \\
Orta & 312 & \\
Düşük & 44 &
\end{tabular}

\section{Veri Toplama Araçları ve Süreçleri}

$\mathrm{Bu}$ çalışmada veriler, uygun örnekleme yöntemi ile çeşitli üniversitelerde öğrenim görmekte olan öğrencilerden Google formlar aracılığıyla online platformda toplanmıştır. Ölçekler uygulanmadan önce araştırmanın hangi amaçla yapıldığı açıklanmış ve gönüllülük esas alınmıştır.

\section{Kişisel Bilgi Formu}

Araştırmaya gönüllü katılan katılımcılara ilişkin cinsiyet, okudukları bölüm ve algılanan sosyoekonomik düzeyleri hakkında bilgi edinmek amacıyla oluşturulmuş kişisel bilgi formu kullanılmıştır.

\section{Öznel İyi Oluş Ölçeği}

46 maddeden oluşan Öznel İyi Oluş Ölçeği, Tuzgöl Dost (2005) tarafından geliştirilmiştir. Ölçek 5'li Likert tipinde cevaplanmaktadır. Ölçek maddelerinin 20 tanesi olumsuz, 26 tanesi olumlu ifade biçimindedir. Olumsuz ifadeler tersine çevrilerek puanlanmaktadır. Ölçekten alınan en yüksek puan 230, en düşük puan 46'dır. Yüksek puanlar, iyi oluş düzeyinin yüksek olduğu anlamına gelmektedir. Ölçek yaşama dair öznel değerlendirmeler ile pozitif ve negatif duygu durumlarını ifade etmektedir. Üniversitede öğrenim görmekte olan 209 öğrenci üzerinde yapılan çalışmada ölçeğin Cronbach alfa güvenirlik katsayıs1 .93 olarak bulunurken; test-tekrar test güvenirlik katsayısı ise .86 olarak saptanmıştır. Yapılan analizler sonucunda ölçme aracının geçerli ve güvenilir bir araç olduğu bulunmuştur.

\section{Öz Düzenlemenin Dikkat Kontrolü Boyutu Ölçeği}

Dikkat Kontrolü Ölçeği Schwarzer, Diehl ve Schmitz (1999) tarafından geliştirilmiş ve Diehl, Semegon ve Schwarzer (2006) tarafından İngilizceye uyarlanmıştır. Öncelikle 16 maddeden oluşan ölçek farklı iki grupla yapılan geçerlik ve güvenirlik çalışmasından sonra 10 maddeye indirilmiştir. 3 madde olumsuz madde olup tersine puanlanmaktadır. Fakat farklı kültürlerde yapılan adaptasyon ile 3 olumsuz madde atılarak 7 maddeye indirilmiştir. Çevik, Haşlaman, Mumcu ve Gökçearslan (2015) tarafindan Türkçeye uyarlanan bu ölçeğin çalışma grubu Ankara'da devlete bağlı bir üniversitede öğrenim gören 389 öğrenciden oluşmaktadır. Ölçek tek faktörden ve toplam 7 maddeden oluşup test-tekrar test güvenirlik katsayısı .67; Cronbach alfa iç tutarlık katsayısı ise .84 olduğu saptanmıştır. Aynı zamanda ölçüt bağıntılı geçerlik için kullanılan Genel Öz Yeterlik Ölçeği ve Akademik Öz Yeterlik Ölçeği ile aralarında anlamlı ve olumlu düzeyde bir ilişkinin olduğu bulunmuştur. Sonuç olarak Öz Düzenlemenin Dikkat Kontrolü Ölçeğinin güvenilir ve geçerli bir ölçme aracı olduğu görülmüştür. 


\section{Ruminatif Düşünce Biçimi Ölçeği}

Ruminatif Düşünce Biçimi Ölçeğini Brinker ve Dozois geliştirmiştir. Karatepe (2010) tarafından Türkçeye uyarlanan bu ölçek 20 maddeden oluşup 7'li Likert tipinde cevaplanmaktadır. 1 (beni hiç tarif etmiyor) ile 7 (beni çok iyi tarif ediyor) şeklinde puanlanmaktadır. Ölçek bireyin o anki ruh halinden ziyade genel ruh durumunu ölçmektedir. Ölçek puanlarının toplamı herhangi bir psikolojik bozukluğu ölçmez ve belirli bir kesme puanı yoktur. Testin Cronbach alfa iç tutarlık katsayısını belirlemek için 350 katılımcıya uygulanmıştır. Test tekrar test korelasyon katsayısının belirlenmesi için 32 katılımcıya test 30 günün ardından tekrar uygulanmıştır. Sonuç olarak Cronbach alfa güvenirlik katsayısı .90 şeklinde bulunurken; test tekrar test korelasyon katsayısı .84 olduğu saptanmıştır. Bu ölçümler sonucunda testin güvenilir ve geçerli bir ölçme aracı olduğu anlaşılmıştır.

\section{Verilerin Analizi}

Araştırmada toplanan veriler test edilmeden önce varsayımlarına incelenmiştir. Kayıp veriler ve ters kodlanan maddeler düzeltildikten hemen sonra normallik varsayımına uygun olduğu görülen verilerle bağımlı ve bağımsız değişkenler arasındaki ilişkileri ortaya koymak için Pearson korelasyonu ve basit doğrusal regresyon analizinden faydalanılmıştır.

\section{Etik}

$\mathrm{Bu}$ çalışmanın aşamalarında toplanan tüm verilerin, bilimsel araştırma ve yayın etiği kurallarına uygun olduğunu, toplanan verilerde hiçbir değişiklik yapılmadığını, herhangi bir etik ihlal ile karşılaşılması halinde sorumluluğun yazarlara ait olduğunu, Necmettin Erbakan Üniversitesi Ereğli Eğitim Fakültesi Dergisi'nin sorumlu olmadığını beyan ederim.

\section{BULGULAR}

$\mathrm{Bu}$ bölümde, araştırma soruları doğrultusunda istatistiksel analizler yapılmıştır ve verilere ilişkin bulgulara yer verilmiştir. Değişkenlere ilişkin ortalama ve standart sapma puanlarının yanında normallik varsayımlarına ilişkin değerler Tablo 2'de yer almaktadır.

\section{Tablo 2.}

Değişkenlere İlişkin Betimleyici İstatistikler

\begin{tabular}{lllll}
\hline Değişkenler & Ortalama & Standart Sapma & Çarpıklık & Basıklık \\
Dikkat Kontrolü & 2.79 & .608 & -.263 & -.259 \\
Öznel İyi Oluş & 3.67 & .667 & -.322 & -.151 \\
Ruminasyon & 4.48 & 1.407 & -.273 & -.849 \\
\hline
\end{tabular}

Normal dağılımın sağlanması için çarpıklık-basıklık değerlerinin +1, -1 (Hair, Black, Babin, Anderson ve Tatham, 2013) veya +2, -2 (George ve Mallery, 2010) arasında değişkenlik göstermesi gerekmektedir. Tablo 2 incelendiğinde bütün değişkenlere ilişkin çarpıklık-basıklık değerlerinin +1 ve -1 arasında değişkenlik gösterdiği bulunmuştur. Dolayısıyla normallik şartının sağlandığı söylenebilir. Buradan yola çıkarak değişkenler arasındaki ilişkiler analiz edilmiş ve bu analizlere ilişkin değerlere Tablo 3'de yer verilmiştir.

\section{Tablo 3.}

Değişkenlere İlişkin Korelasyonlar

\begin{tabular}{llll}
\hline Değişkenler & 1 & 2 & 3 \\
1.Dikkat kontrolü & - & $.467^{* *}$ & -.075 \\
2.Öznel iyi oluş & & - & $-.250^{* *}$ \\
\hline
\end{tabular}


3.Ruminasyon

$* * p<.01$

Tablo 3'te dikkat kontrolü ile öznel iyi oluş arasında pozitif doğrultuda, orta düzeyde bir ilişki olduğu saptanmıştır $(\mathrm{r}=.467, p<.01)$. Bunun yanı sıra öznel iyi oluş ve ruminasyon arasında negatif yönde düşük düzeyde bir ilişkinin olduğu bulunurken $(\mathrm{r}=-.250, p<.01)$; ruminasyon ve dikkat kontrolü arasında istatistiksel bir ilişkinin olmadığ 1 görülmüştür $(r=-.075, p>.05)$.

Araştırmada yer alan değişkenler arasındaki ilişkiler incelendikten sonra basit doğrusal regresyon analizinden yararlanılmıştır. Basit doğrusal regresyon analizi yapılmadan önce bir takım varsayımlar incelenmiştir. İncelemeler sonucunda değişkenlerin en az eşit aralıklı ölçek düzeyinde toplandığı, aralarında doğrusal bir ilişkinin olduğu ve noktaların bir eksen etrafında kümelendiği bulunmuştur. Dolayısıyla puanların normal dağılım gösterdiği saptanmıştır. Araştırmada ruminasyon ile dikkat kontrolü arasında anlamlı bir ilişki bulunmadığından, bu değişken regresyon analizi dışında bırakılmış sadece öznel iyi oluş değişkeni modele dahil edilmiştir. Tablo 4'de regresyon analizi sonuçları yer almaktadır.

Tablo 4.

Regresyon Analizi Bulgulart

\begin{tabular}{lllllll}
\hline Değişken & $B$ & $\beta$ & $T$ & $p$ & $R$ & $R^{2}$ \\
Sabit & .855 & & 4.620 & .000 & .483 & .234 \\
Öznel İyi Oluş & .531 & .483 & 10.596 & .000 & & \\
\hline
\end{tabular}

$\mathrm{F}=112.270 ;{ }^{* * *} \mathrm{p}<.001$

Tablo 4' de üniversite öğrencilerinin dikkat kontrolünün, öznel iyi oluş ile orta düzeyde pozitif bir ilişki olduğu ve öznel iyi oluşun dikkat kontrolünü anlamlı şekilde yordadığı $(\beta=.483, p<.001)$ görülmektedir. $\mathrm{R}$ kare değeri; yordayıcı değişkenin, yordanan değişkendeki toplam değişim oranını açıklamaktadır. Buradan hareketle öznel iyi oluşun, dikkat kontrolündeki değişimin \% 23'ünü açıkladığı ve oluşturulan modelin istatistiksel olarak anlamlı olduğu anlaşılmıştır $\left(R^{2}=.234, F=112.270, p<.001\right)$. Bu sonuca göre öznel iyi oluş dikkat kontrolünü pozitif ve anlamlı bir şekilde yordamaktadır

\section{TARTIŞMA ve SONUÇ}

Araştırma sonucunda dikkat kontrolü ve öznel iyi oluş arasında orta düzeyde pozitif bir ilişki bulunurken, ruminasyon ile aralarında anlamlı bir ilişki bulunmamıştır. Bununla birlikte öznel iyi oluş ve ruminasyon arasında negatif yönlü düşük düzeyde bir ilişkinin olduğu saptanmıştır. Regresyon analizi sonucuna göre ise dikkat kontrolünün öznel iyi oluş tarafından anlamlı şekilde yordandığı ve dikkat kontrolünün \%23'ünü açıkladığı bulunmuştur. Gerçekleştirilen korelasyon analizleri sonucunda ruminasyon ile dikkat kontrolü arasında anlamlı bir ilişki bulunmadığı için ruminasyon değişkeni regresyon analizlerine dahil edilmemiştir. Ruminasyon, bireylerde istemsizce ortaya çıkan ve sürdürmekte oldukları eylemlere engel olan bir güçlük olarak tanımlanmaktadır ve bireyler ruminasyonu engellemek için çaba harcamaktadırlar(Clark ve Rhyno, 2005). Bu araştırmada ruminasyonun dikkat kontrolü ile ilişkili çıkmama sebebinin, ruminasyon ölçeğini doldururken katılımcıların içinde bulunduğu durumsal faktörlerden kaynaklanabileceği düşünülmektedir. Zira ruminatif düşünce biçimi ölçeği bireyin genel olarak patalojik ve istemli olmayan düşüncelerini yansıtmaktadır. Oysa katılımcıların; o anki ruh durumlarına dayalı olarak ölçeği cevaplandırmaları, ölçeğin amacına ulaşmasını engellemiş olabilir.

Ruminasyon son yıllarda araştırılmaya değer bir konu olarak görülmüş ve farklı kuramcılara göre farklı şekillerde değerlendirilmiştir. Tepki biçimleri kuramına göre ruminasyon; bireyin depresyon durumundaki semptomlarına, depresyon durumuna neden olabilecek sebep ve sonuçlara tepki olarak çıktığını belirtmektedir (Nolen-Hoeksema, 1991). Öz düzenleyici işlevler kuramına göre var olan durum ile hedeflenen durum arasındaki dengesizlikten kaynaklı ruminasyon oluşmaktadır(Wells ve Matthews, 1996). Üzüntüye ilişkin ruminasyon kuramına göre şu anda içinde bulunduğu üzüntüye dair sürekli düşüncelerden 
oluşmaktadır(Conway, Csank, Holm ve Blake, 2000). Hedefe ilerleme kuramına göre ise tamamlanmamış, gerçekleştirilememiş hedefler hakkında sürekli düşünme olarak ele alınmıştır. Hedefe ilerleme kuramında ruminasyon yarım kalan hedeflerin üzerinde düşünerek alternatifleri görmek bakımından değerlendirildiği için ruminasyona olumlu bakılmaktadır(Martin, Shrira ve Startup, 2004). Bu araştırmada ruminasyon dikkati dağıtıcı bir değişken olarak ele alınsa da ruminasyonun hedefleri gerçekleştirirken yeniden bir düzenleme olanağı sağlaması araştırma sonucunun beklenildiği gibi çıkmaması sonucunu açıklayabilir.

Araştırmada öznel iyi oluşun dikkat kontrolünün yordayan önemli bir kavram olduğu ve öznel iyi oluş arttıkça dikkat kontrolünün de arttığı bulunmuştur. Teorik olarak olumlu anılar, anlamlı yaşantılar, olumlu duygulanımlar ve iyimserlik gibi bileşenleri içeren öznel iyi oluş ile dikkat kontrolü arasındaki ilişkiyi doğrudan ortaya koymaya yönelik olarak yapılan araştırmalar literatürde yer almamaktadır. Fakat Musch ve Klauer (2003), olumsuz olayların olumlu olaylardan daha fazla dikkat çekme eğiliminde olduğunu ve bellekte daha erişilebilir bir şekilde saklandığını ifade etmektedir. Robinson, Meier ve Vargas (2005) problemli durumlarda bulunan bireylerin problem durumlarından kaçınmak için dikkatlerini dağıtmaya yöneldikleri bulunmuştur. Larsen (1993) ise benzer şekilde dikkat dağılmasının üniversite öğrencileri arasında ruhsal durumu düzenleme stratejisi olarak kullanıldığını ifade etmektedir. Robinson ve Compton (2008), öznel iyi oluş ile seçici dikkatin sıklıkla etkileşim içinde olduğunu ifade etmektedir. Bütün bu bulgular öznel iyi oluş ile dikkat arasındaki ilişkiye işaret etmektedir. Nitekim bu çalışmada elde edilen bulgularda; benzer şekilde öznel iyi oluşu, dikkat kontrolünü anlamlı bir şekilde yordadığı yönündedir. İncelenen çalışmalar öznel iyi oluşu artıran bir faktör olarak dikkatin olumlu deneyimlere yönlendirilmesini gösteriyor olsa da bu çalışmada elde edilen bulgularla birlikte bu sürecin birbirini etkileyen dönüşümsel bir niteliğe sahip olduğu görülmektedir. Nitekim bireylerin öznel iyi oluş düzeyleri arttıkça artan dikkat kontrolü, yaşamlarını olumlu değerlendiren bireylerin dikkatlerini daha iyi kontrol edebildiğini gösterir niteliktedir.

Öznel iyi oluş düzeyi yüksek bireylerin yaşamlarına ilişkin genel anlamda olumlu değerlendirmelere sahip oldukları bilinmektedir. Bu doğrultuda bu bireylerin psikolojik problemlerle karşılaşma ihtimalinin daha düşük düzeyde olması beklenir. Luszczynska ve arkadaşları (2004), öz düzenlemeyi kişinin olumsuz duyguları kontrol etme yeteneği olarak ifade eder ve bu nedenle daha iyi öz kontrol becerilerinin yani dikkat kontrolünün daha yüksek düzeyde öznel iyi oluş ile ilişkili olacağını dile getirir. Reinholdt-Dunne, Mogg ve Bradley (2013), dikkat kontrolündeki bireysel farklılıkların kaygı ve depresyon ile ilişkili olduğunu bulgulamıştır ve dikkat kontrolünün zayıf olduğu bireylerin daha yüksek depresyon puanlarına sahip olduğunu ifade etmektedir. Reinholdt-Dunne, Mogg ve Bradley (2009) yüksek kaygı ve zayıf dikkat kontrolünün duygusal olarak göze çarpan bilgilerin işlenişini artırdığını öngörmektedir. Keilp ve arkadaşları (2013) ise dikkat kontrolünde yaşanan problemlerin intihar düşünceleri veya davranışıyla ilişkili olduğunu ifade etmektedir. Bu bulgular öznel iyi oluş düzeyinin daha yüksek olduğu bireylerde daha az psikolojik problemler yaşanacağına ilişkin araştırma sorusunu destekler niteliktedir ve bunun yanında öznel iyi oluş ile dikkat kontrolü arasındaki ilişkinin önemini de ortaya koymaktadır.

Uzun yıllar boyunca araştırmalar patoloji ve olumsuz davranışlar üzerine yapılmıştır. Buradan hareketle dikkat kontrolünü sağlamaktan çok, dikkat eksikliğinin olumsuz sonuçlarına daha fazla değinilmiştir. Bu noktada dikkat eksikliği ve hiperaktivite bozukluğuna değinmek yararlı olacaktır. Süregiden bir dikkatsizlik ile kategorize edilen dikkat eksikliği ve hiperaktivite bozukluğunda (Yavuz ve Doğangün, 2011) da düşük düzeyde dikkat kontrolünden bahsedilebilir. Aydın (2019) bireylerin DEHB seviyesi arttıkça depresyon seviyesinin de arttığını bulgulamıştır. Benzer olarak Çeben'in (2016) araştırmasında da DEHB' li bireylerin depresyon düzeylerinin ise daha yüksek olduğu bulunmuştur. Bir diğer çalışmada ise dikkat eksikliği bulunan çocukların bulunmayan çocuklara göre benlik saygısı puanlarının daha düşük olduğu saptanmıştır (Göker, 2019; Shaw-Zirt, Popali-Lehane, Chaplin, \& Bergman, 2005). Ayrıca DEHB’li bireylerde eş olarak görülen ve en çok rastlanılan bozukluklardan birinin anksiyete bozukluğu olduğu ifade edilmektedir (Aysev ve Öner, 2001; Çuhadaroğlu vd., 2007; Gümüş, 2011). Bu bulgularda DEHB yaşayan bireylerin öznel iyi 
oluş düzeylerini olumsuz yönde etkileyecek psikolojik problemlerle baş etmek durumunda kaldığını göstermektedir. Dikkati çeken nokta ise burada da dikkat problemlerinin karşımıza çıkmış olmasıdır.

\section{ÖNERÍLER}

Literatür incelendiğinde dikkat kontrolü ile öznel iyi oluş gibi kişisel yapıların ilişkisini inceleyen ve bağımlı değişken olan dikkat kontrolünü açıklayan değişkenlere ilişkin çalışmalara çok az rastlanmaktadır. Ayrıca değinilen araştırmalar dikkate alındığında çoğunlukla dikkat eksikliği ve hiperaktivite bozukluğu bağlamında çalışmalar yapıldığı görülmektedir. Dikkat kontrolünün sadece DEHB tanısı konulmuş olan bireyler için değil tüm bireyler için önemli olduğu düşünülmektedir. Zira görülmektedir ki dikkat kontrolü sadece bilişsel becerileri hedef alan konularda değil kişinin öznel iyi oluşu gibi psikolojik bağlamda da önemli bir etkendir. Bu durum dikkate alınırsa problem ortaya çıkmadan önce yapılabilecek çalışmaların dikkat kontrolünü sağlamada aktif bir rol oynayacağı düşünülmektedir. Örneğin dikkat kontrolünün etkin bir biçimde sağlanması için sağlıklı beslenme, düzenli uyku, spor aktiviteleri işe yarayabilmektedir. Bu tarz etkinliklerin öznel iyi oluşu arttırdığı da göz önünde bulundurulursa dikkat kontrol düzeyini de arttırabilecekleri düşünülmektedir.

Dikkat kontrolünü yeterli düzeyde sağlayabilen birey; duygu, düşünce ve davranışlarını daha bilinçli olarak düzenleyebileceğinden yaşamda karşılaşabileceği zorluklar ile etkin bir şekilde mücadele edebilecektir. Öznel iyi oluş düzeyinin dikkat kontrolünü anlamlı bir şekilde yordadığı düşünülürse üniversite öğrencileri için öznel iyi oluşu arttırabilecek psiko-eğitim gruplarının, bireyle ve grupla psikolojik danışma uygulamalarının dikkat kontrolünü de olumlu yönde etkileyeceği ve dolaylı olarak da bilişsel yeterlikler üzerinde önemli katkılar sağlayabileceği düşünülmektedir.

Dikkat kontrolü, bir hedef doğrultusunda uygun etkinlikleri seçmeyi, uygun olmayan etkinlikleri elemeyi sağlamaktadır. Bu sayede hem zaman tasarrufu sağlamakta hem de hedefe ulaşırken gereğinden fazla çabayı engellemektedir. Bu araştırma üniversite öğrencileriyle gerçekleştirilmiştir. Dikkat kontrolünün öğrenme yaşantılarında önemli bir bileşen olduğu düşünülürse; daha küçük yaştaki bireylerle (ilkokul, ortaokul, lise) araştırma tekrarlanabilir. Sonuçlar 1şı̆̆ında okullarda dikkat kontrolünü geliştirmeye yönelik eğitim programları hazırlanabilir ve rehberlik müfredatında yer alması önerilebilir.

Bu araştırmada dikkat kontrolünü açıklayabilecek ya da ilişkili olabilecek birkaç değişkene yer verilmiştir. İlerleyen çalışmalarda kişilik özellikleri, madde kullanımı (kafein, nikotin), toplam uyku saati gibi farklı değişkenlerin araştırılması da önemli görülmektedir.

\section{KAYNAKÇA}

Alçay, E. S. (2019). Ergenlerde problemli internet kullanımı ile bilinçli farkındalık ve öz düzenleme arasındaki ilişkilerin incelenmesi. (Yayımlanmamış Yüksek Lisans Tezi), Akdeniz Üniversitesi, Mersin.

Aydın, A. (2004). Gelişim ve öğrenme psikolojisi. Ankara: Tekağaç Eylül Yayınları.

Aydın, Ş. (2019). Bir grup lise öğrencisinin dikkat eksikliği ve hiperaktivite bozukluğu kendi bildirim düzeyleri ile sosyal anksiyete ve depresyon düzeyleri arasındaki ilişkinin incelenmesi. (Yayımlanmamış Yüksek Lisans Tezi), Maltepe Üniversitesi, İstanbul.

Aysev, A. \& Öner, P. (2001). Çocuklukta DEHB tanısı almış olguların ergen görünümleri. Çocuk ve Gençlik Ruh Să̆lı̆̆ Dergisi, 8(3) 127-131.

Bakır, T. (2016). Doğal çevrenin çocukların öz düzenleme becerisi ve uyumları üzerindeki rolü. (Yayımlanmamış Yüksek Lisans Tezi), Orta Doğu Teknik Üniversitesi, Ankara.

Baumeister, R. F. \& Heatherton, T. F. (1996). Self-regulation failure: An overview. Psychological Inquiry, 7(1), 1-15.

Berger, A., Kofman, O., Livneh, U. \& Henik, A. (2007). Multidisciplinary perspectives on attention and the development of self-regulation. Progress in Nurobiology, 82(5), 256-286. 
Brunstein, J. C. (1993). Personal goals and subjective well-being: A longitudinal study. Journal of Personality and Social Psychology, 65(5), 1061.

Büyüköztürk, Ş., Çakmak, E. K., Akgün, Ö. E., Karadeniz, Ş. \& Demirel, F. (2017). Bilimsel Araştırma Yöntemleri. Ankara: Pegem Akademi.

Clark, D. A. \& Rhyno, S. (2005). Unwanted Intrusive Thoughts in Nonclinical Individuals: Implications for Clinical Disorders. In D. A. Clark (Ed.), Intrusive thoughts in clinical disorders: Theory, research, and treatment (p. 1-29). Guilford Press.

Conway, M., Csank, P. A., Holm, S. L. \& Blake, C. K. (2000). On assessing individual differences in rumination on sadness. Journal of Personality Assessment, 75(3), 404-425.

Çeben, K. (2016). Dikkat eksikliği hiperaktivite bozukluğu tanısı almış ve almamış çocukların yönetici işlevler, benlik saygısı ve depresyon düzeylerinin incelenmesi. (Yayımlanmamış Yüksek Lisans Tezi), Beykent Üniversitesi, İstanbul.

Çevik, Y. D., Haşlaman, T., Mumcu, F. K. \& Gökçearslan, Ş. (2017). Öz düzenlemenin dikkat kontrolü boyutu: Bir ölçek uyarlama çalışması. Başkent Üniversitesi Ĕgitim Dergisi, 2(2), 229-238.

Çuhadaroğlu, Ç. F., Ulay T., Dinç G., Tüzün Z., Evinç G. \& Tasgın E. (2007). Çocuklukta dikkat eksikliği hiperaktivite rahatsızlığı (DEHB) tanısı almış olan ergenlerde psikiyatrik komorbidite. HÜTF Bilimsel Araştırmalar Birimi Destekli Tamamlanmış Proje, Proje No : 0501101008, Ankara.

Diehl, M., Semegon, A. B. \& Schwarzer, R. (2006). Assessing attention control in goal pursuit: a component of dispositional self-regulation. Journal of Personality Assessment, 86(3), 306-317.

Diener, E. (2000). The science of happiness and a proposal for a national index. American Psychologist, 70(3), 234-242.

Diener, E. \& Chan, M. Y. (2011). Happy people live longer: Subjective well-being contributes to health and longevity. Applied Psychology: Health and Well-Being, 3(1), 1-43.

Diener, E., Oishi, S. \& Lucas, R. E. (2003). Personality, culture, and subjective well-being: Emotional and cognitive evaluations of life. Annual Review of Psychology, 54(1), 403-425.

Doğangün, B. \& Yavuz, M. (2011). Dikkat eksikliği hiperaktivite bozukluğu. Türk Pediatri Arşivi, 46.

Donaldson, C., Lam, D. \& Mathews, A. (2007). Rumination and attention in major depression. Behaviour Research and Therapy, 45(11), 2664-2678.

Duran, E. (2019). Anne baba tutumu ile çevrim içi oyun bağımlılı̆̆ı arasındaki ilişside öz düzenlemenin aracı rolü. (Yayımlanmamış Yüksek Lisans Tezi), Gaziosmanpaşa Üniversitesi, Tokat.

Eisenberg, N., Fabes, R. A., Guthrie, I. K. \& Reiser, M. (2000). Dispositional emotionality and regulation: their role in predicting quality of social functioning. Journal of Personality and Social Psychology, 78(1), 136.

Gasper, K. \& Clore, G. L. (2002). Attending to the big picture: Mood and global versus local processing of visual information. Psychological Science, 13(1), 34-40.

George, D. \& Mallery, M. (2010). Spss for windows step by step: A simple guide and reference (10th ed.). Boston: Pearson

Gökçearslan, Ş., Mumcu, F. K., Haşlaman, T. \& Çevik, Y. D. (2016). Modelling smartphone addiction: the role of smartphone usage, self-regulation, general self-efficacy and cyberloafing in university students. Computers in Human Behavior, 63, 639-649.

Göker, Z. (2009). Dikkat eksikliği hiperaktivite bozukluğu bulunan çocuk ve ergenlerin benlik saygısı ve yaşam kalitesinin değerlendirilmesi. (Tıpta Uzmanlık Tezi), Karadeniz Teknik Üniversitesi, Trabzon.

Gümüş, Y. Y. (2011). Dikkat eksikliği hiperaktivite bozukluğu tanısı alan çocuklarda anksiyete bozukluğu eşhastalanımı yaygınlı̆̆ . (Tıpta Uzmanlık Tezi), Kocaeli Üniversitesi, Kocaeli.

Hair, J. F., Black, W. C., Babin, B. J., Anderson, R. E. \& Tatham, R. L. (2013). Multivariate data analysis. Londra: Pearson Education Limited.

Hofmann, W., Schmeichel, B. J. \& Baddeley, A. D. (2012). Executive functions and self-regulation. Trends in Cognitive Sciences, 16(3), 174-180.

Karatepe, H. T. (2010). Ruminatif Düşünme Biçimi Ölçeğinin Türkçe uyarlamast, geçerlik ve güvenirlik çalışması. (Yayınlanmamış Uzmanlık Tezi), T.C. Sağlık Bakanlığı, İstanbul.

Keilp, J. G., Gorlyn, M., Russell, M., Oquendo, M. A., Burke, A. K., Harkavy-Friedman, J. \& Mann, J. J. 
(2013). Neuropsychological function and suicidal behavior: attention control, memory and executive dysfunction in suicide attempt. Psychological Medicine, 43(3), 539-551.

Larsen, R. J. (1993, August). Mood regulation in everyday life. In D. M. Tice (Chair), Self-regulation of mood and emotion. Symposium conducted at the 101st Annual Convention of the American Psychological Association, Toronto, Canada.

Luszczynska, A., Diehl, M., Gutiérrez-Dona, B., Kuusinen, P. \& Schwarzer, R. (2004). Measuring one component of dispositional self-regulation: Attention control in goal pursuit. Personality and Individual Differences, 37(3), 555-566.

Martin, L. L., Shrira, I. \& Startup, H.M. (2004) Rumination as a function of goal progress, stop rules, and cerebral lateralization. In Papageiorgio C, Wells A (Eds.), Depressive rumination nature, theory and treatment. West Sussex: John Wiley and Sons Ltd.

Matthews, G. \& Wells, A. (2008). Rumination, depression and metacognition: S-REF model. In Papageorgiou C. \& Wells, A. (Eds.), Depressive rumination: Nature theory and treatment (pp. 125151). New Jersey: John Wiley \& Sons Press.

Muris, P., Meesters, C. \& Rompelberg, L. (2007). Attention control in middle childhood: Relations to psychopathological symptoms and threat perception distortions. Behaviour Research and Therapy, 45(5), 997-1010.

Musch, J., \& Klauer, K. C. (2003). The psychology of evaluation. Mahwah, NJ: Erlbaum.

Myers, D. G. \& Diener, E. (1995). Who is happy?. Psychological Science, 6(1), 10-19.

Nolen-Hoeksema, S. (1991). Responses to depression and their effects on the duration of depressive episodes. Journal of Abnormal Psychology, 100(4), 569-582.

Nolen-Hoeksema, S., Wisco, B. E., \& Lyubomirsky, S. (2008). Rethinking rumination. Perspectives on Psychological Science, 3(5), 400-424.

Reinholdt-Dunne, M. L., Mogg, K. \& Bradley, B. P. (2009). Effects of anxiety and attention control on processing pictorial and linguistic emotional information. Behaviour Research and Therapy, 47(5), 410-417.

Reinholdt-Dunne, M. L., Mogg, K. \& Bradley, B. P. (2013). Attention control: Relationships between selfreport and behavioural measures, and symptoms of anxiety and depression. Cognition \& Emotion, 27(3), 430-440.

Robinson, M. D. \& Compton, R. J. (2008). The happy mind in action. The cognitive basis of subjective well-being. In M. Eid \& R. J. Larsen (Ed.), The science of subjective well-being (pp. 220-238). NewYork: The Guilford Press.

Robinson, M. D., Meier, B. P. \& Vargas, P. T. (2005). Extroversion, threat categorizations, and negative affect: A reaction time approach to avoidance motivation. Journal of Personality, 73, 1397-1436.

Rueda, M. R., Posner, M. I. \& Rothbart, M. K. (2004). Attentional control and self-regulation. Handbook of self-regulation: Research, theory, and applications, 2, 284-299.

Shaw-Zirt, B., Popali-Lehane, L., Chaplin, W. \& Bergman, A. (2005). Adjustment, social skills, and selfesteem in college students with symptoms of ADHD. Journal of Attention Disorders, 8(3), 109-120.

Soysal, A. Ş., Yalçin, K. \& Can, H. (2008). Bilişsel psikoloji kapsamında yer alan dikkat teorileri. Yeni Sempozyum: Psikiyatri, Nöroloji ve Davranış Bilimleri Dergisi. Cerrahpaşa Tip Fakültesi Psikiyatri Kliniği Vakfi.

Suh, D. Y. (2016). Effects of negative self-evaluation bias on depression, rumination, and distractibility. Yale Review of Undergraduate Research in Psychology, 49, 49-59.

Şata, M. (2017). Examining the variables effecting the controls attention of high school students using chaid analysis Dicle University, Journal of Ziya Gökalp Faculty of Education, 30, 465-475.

Tuzgöl Dost, M. (2005). Öznel İyi Oluş Ölçeğinin geliştirilmesi: geçerlik ve güvenirlik çalışması. Türk Psikolojik Danışma ve Rehberlik Dergisi, 3(23), 103-111.

Wells, A. ve Matthews, G. (1996). Modelling cognition in emotional disorder: The S-REF model. Behaviour Research and Therapy, 34(11), 881-888.

Whitmer, A. J. \& Gotlib, I. H. (2013). An attentional scope model of rumination. Psychological Bulletin, 139(5), 1036. 
Yay, M. (2018). Problemli akıllı telefon kullanımı ve kendini sabotaj ilişkisinde öz düzenlemenin aracı rolünün incelenmesi. (Yayımlanmamış Yüksek Lisans Tezi). Hasan Kalyoncu Üniversitesi, Gaziantep.

Zimmerman, B. J. (2000). Attaining self-regulation: A social cognitive perspective. In Boekaerts, M., Zeidner, M. \& Pintrich, P. R. (Eds.). Handbook of self-regulation. (pp. 13-39). London: Academic Press.

\section{EXTENDED ABSTRACT}

Introduction: Attention control, a component of self-regulation, is defined as the ability to regulate and control internal and external stimuli that distract a person's mind, and to achieve and focus on desired goals or results. The concept of subjective well-being that includes emotional and cognitive evaluations of people's lives and life satisfaction may be closely related to individuals' attention processes. It can be stated that the concept of rumination, which is used to express the recurring thoughts of the individual about their personal problems, involuntary and unintentional experiences, has a negative relationship with attention control. This study aimed to relationships of attention control, which is considered as an important factor, with subjective well-being and rumination, two concepts that show different aspects in terms of psychological effects.

Materials and Methods: The aim of this study is to examine the relationships between attention control, subjective well-being and rumination. Scanning model was used in this study. The dependent variable of the research is attention control and independent variables are subjective well-being and rumination. The study group consists of 370 university students. The data of the study were obtained using the Subjective Well-being Scale, the Attention Control Dimension of Self-Regulation Scale, the Ruminative Thinking Style Scale and the personal information form developed by the researchers. Pearson's correlation and simple linear regression analysis were using by SPSS.

Findings: $286(77.3 \%)$ of the participants are women and $84(22.7 \%)$ are men. It was found that there is a moderate positive correlation between attention control and subjective well-being $(r=.467, p<.01)$. While it was found that there is a low-level negative relationship between subjective well-being and rumination $(r=-.250, p$ $<.01)$; It was found that there was no significant relationship between rumination and attention control $(\mathrm{r}=-.075$, $\mathrm{p}>$.05). Only subjective well-being was included in the regression model. Since there was no significant relationship between rumination, another variable of the study, and attention control, this variable was excluded from the regression analysis. According to the regression analysis results, attention control is moderately positive related to subjective well-being and subjective well-being significantly predicts attention control $(\beta=.483, \mathrm{p}<$ $.001)$.

Discussion: In the study, it was found that subjective well-being is an important predictor of attention control and as subjective well-being increases, attention control also increases. Robinson, Meier, and Vargas (2005) state that individuals in problematic situations tend to distract themselves to avoid problem situations, while Larsen (1993) states that distraction is used as a mental state regulation strategy among university students. Robinson and Compton (2008) state that subjective well-being and selective attention frequently interact. Although the studies examined show that attention is directed to positive experiences as a factor that increases subjective well-being, it is seen that this process has a transformational quality that affects each other with the findings obtained in this study. Attention control, which increases as the subjective well-being levels of individuals increase, shows that individuals who evaluate their lives positively can control their attention better. The literature tended to reveal the contributions of attention control to subjective well-being in the relationship between attention control and subjective well-being, but with this study, it is seen that subjective well-being is an important predictor of attention control. This finding shows that the variables affect each other cyclically. It can be stated that the increase in subjective well-being of individuals who have more positive evaluations about their lives contributes positively to attention control.

\section{Conclusion and Suggestions:}

When the literature is examined, there are very few studies on variables that examine the relationship of personal structures such as attention control and subjective well-being and explain the dependent variable attention control. Also, considering the mentioned studies, it is seen that studies are mostly conducted in the context of attention 
deficit and hyperactivity disorder. Attention control is thought to be important not only for individuals diagnosed with ADHD but also for all individuals. Because it is seen that attention control is an important factor not only in subjects targeting cognitive skills but also in a psychological context such as the subjective well-being of the individual. Considering this situation, it is thought that the studies that can be done before the problem occurs will play an active role in providing attention control. For example, a healthy diet, regular sleep, and sports activities can be helpful for effective attention control. Considering that such activities increase subjective well-being, it is thought that they may increase the level of attention control.

An individual who can provide sufficient attention control; will be able to fight effectively with the difficulties he may encounter in life as he can regulate his emotions, thoughts, and behaviors more consciously. Considering that subjective well-being level significantly predicts attention control, it is thought that psycho-education groups, which can increase subjective well-being for university students, and psychological counseling practices with individuals and groups will also positively affect attention control and indirectly contribute to cognitive competencies.

Attention control enables selecting appropriate activities towards a goal and eliminating unsuitable activities. In this way, it both saves time and prevents unnecessary effort while reaching the target. This research was conducted with university students. Considering that attention control is an important component in learning experiences; The research can be repeated with younger individuals (primary school, middle school, high school). In light of the results, training programs to improve attention control in schools can be prepared and recommended to be included in the guidance curriculum.

In this study, several variables that may explain or be related to attention control are included. It is also important to investigate different variables such as personality traits, substance use (caffeine, nicotine), and total sleep time in future studies. 